\title{
Conflict between science and superstition in medical and dental
}

\section{practices}

Donat Uwayezu (1), Eustache Ntigura (1), Agnes Gatarayiha (1), Sarah Erem (2), Anwarul A. Majumder ${ }^{(3)}$, Mainul Haque (4) \& Mohammed S. Razzaque $(1,2,5)$

${ }^{1}$ Department of Preventive \& Community Dentistry, University of Rwanda School of Dentistry, Kigali, Rwanda

2Department of Pathology, Saba University School of Medicine, Saba, Dutch Caribbean ${ }^{3}$ Medical Education, Faculty of Medical Sciences, Cave Hill Campus, University of the West Indies, Barbados

${ }^{4}$ Unit of Pharmacology, Faculty of Medicine and Defense Health, Universiti Pertahanan Nasional Malaysia (National Defense University of Malaysia), Kem Sungai Besi, Kuala Lumpur, Malaysia

${ }^{5}$ Department of Pathology, Lake Erie College of Osteopathic Medicine, Erie, PA, USA

Address of correspondence:

Mohammed S. Razzaque, MBBS, PhD, Department of Pathology, Lake Erie College of Osteopathic Medicine, 1858 West Grandview Boulevard, Room: B2-306, Erie, PA 16509, USA. E-mails: mrazzaque@lecom.edu 


\section{Abstract}

Superstition is a belief that is not based on scientific knowledge. Traditional healers usually use superstition in their practices to manage human health problems and diseases; such practices create a conflict with the medical profession and its evidencebased practices. Medical professionals confirm that this kind of practice is not safe to human health as it is done by untrained people (e.g., tradition healers) utilizing unsterilized instruments within unhygienic environments. Most of the cases eventually develop a variety of complications, which are sometimes fatal. Female genital mutilation, uvulectomy, oral mutilation (tooth bud extraction to cure "Ibyinyo"), and eyebrow incisions are examples of the many different types of superstitious practices which occur commonly in different parts of the world. We described how these traditional practices of superstition have been and continue to be performed in various parts of the world, their complications on oral and general health, and the ways such practices hinder modern medical practices. This paper aims to increase the awareness of these superstition-driven traditional and potentially harmful practices by promoting the importance of evidencebased medical practices.

Key words: Sperstition, Traditional healer, Conflict, Clinical practice 


\section{Introduction}

Science can be broadly defined as an organized system for collecting knowledge. The goal of science is to understand the nature of the world and the universe. It is based on the assumption that there is an objective reality to the universe that can be observed by a rational mind. These observable truths are the facts that form the basis for rational assumptions $[1,2]$. Historically, science consisted simply of making observations to gain deeper understandings of natural phenomena. In modern science, the laws of nature are determined through a rigorous process of scientific analysis. Experiments are meticulously conducted to test a hypothesis based on existing knowledge, and data is recorded in detail so it can be evaluated for accuracy and reproducibility by others $[1,3]$.

In the modern day, medicine is considered by many to be a branch of science [4]. The term "Medical science" is broad and encompasses a myriad of disciplines, and it covers both the basic science (knowledge of the normal functions of the human body and the etiology of diseases) and applied science (methods and instruments for diagnosing, treating, and preventing diseases). Medical research is the process of conducting experiments to expand knowledge of human health and diseases to develop and improve upon existing practices. The goal is to use empirical evidence to guide standards that will maximize beneficial health outcomes and minimize potential harm from medical practices $[2,5]$.

Historically, medicine was practiced more as an art with connections to religious or philosophical practices. Today, however, medicine follows the same rigorous principals 
of observation, experimentation, and evaluation as other areas of science. Evidencebased medicine is now the gold-standard for medical and dental practices, and many healthcare monitoring organizations, including United States Food and Drug Administration (FDA) and the European Commission require strong scientific evidence for the safety and efficacy of drugs, medical devices, and procedures before approving them for use in their respective countries. Similarly, any healthcare practitioner licensed in most countries must have received accredited evidence-based medical education $[2,4,6]$.

\section{Superstition}

Superstition is the non-scientific belief in the mystic connection. Such beliefs include aspects of certain religions as well as supernatural ideologies like astrology, omens, witchcraft, and prophecies [7]. These are notions that are still maintained by some despite evidence to the contrary. An example of a superstition is the concoction of a mystical recipe to ward off evil spirits that cause disease [8]. Even after all the modernization and/or enlightenment that has taken place, superstitious beliefs persist in our societies. It is thought that most of the human being to a certain level believes in such irrational superstitious views $[9,10]$ 


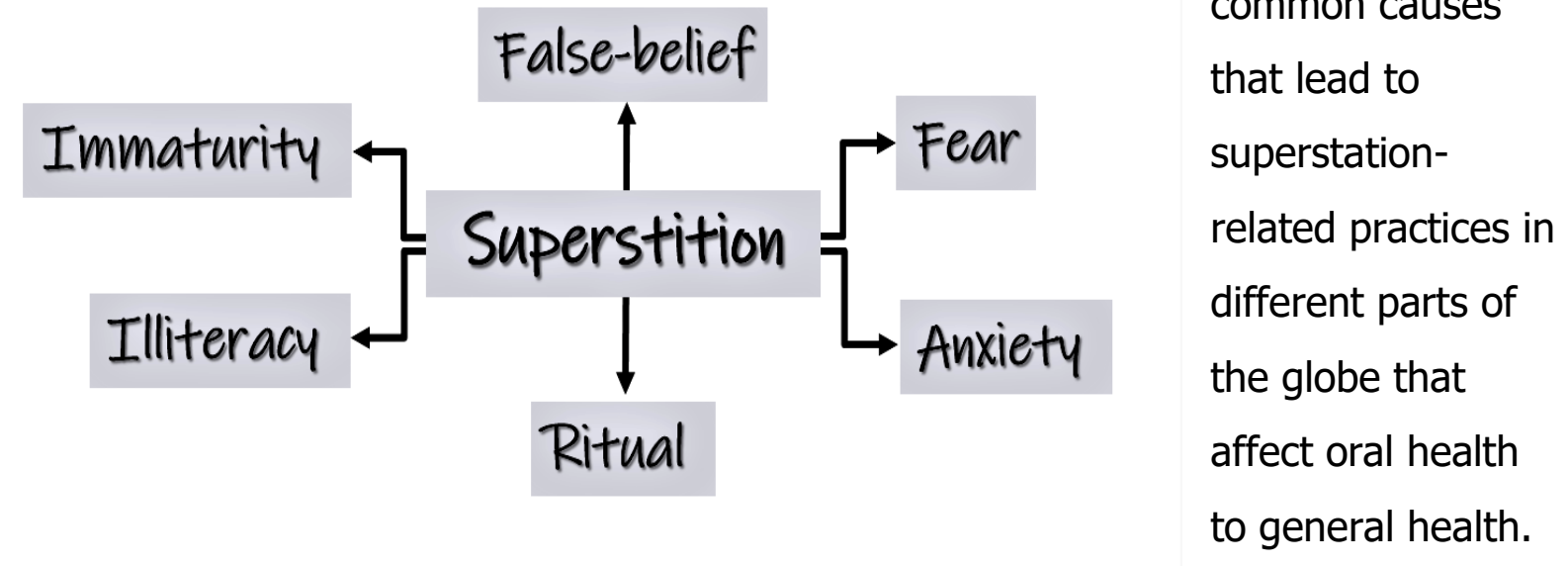

The superstition is mostly resulted from illiteracy, immaturity, and anxiety of the unknown, usually related to the incorrect clarification of natural events (Figure 1). Superstitions could have religious, cultural, and personal basis [8]. Of relevance, religious principles and practices may appear superstitious to the person without faith. There has been an enormous and diverse array of cultural and ritual superstitions in many communities throughout history. Many cultures have held illogical views concerning ways to ward off illness, bring good fortune, predict the future, avert disease or accidents, and even choosing the mate [11]. Even a medical student who does well in a professional examination may begin to think their success is due to the use of a certain pen, and that the pen, therefore, is lucky; a gambler wins a few times after betting on a black horse and starts believing that black horses run well for him or her [12]. Such irrational justifications are partly based on not trusting the fact that individuals have full control of events that they are involved; lack of self-believe could lead to fear, and put faith in 
falsehoods to feel safe and secure [9]. Some superstitious beliefs stem from misunderstandings of natural physiological processes. For example, in many communities, female menstruation was (and in some cases still is) considered "unclean" $[13,14]$. While menstruating, women were not allowed to visit a temple or touch a pickle (for fear of spoiling it); these menstruating, women also were not allowed to touch other people and commonly had to sit in a separate room and eat from a separate plate from fear of spreading contamination. Even in the UK, many farmers' wives believed that milk handled during menstruation could not be churned into butter or that hams would not take salt from their hands, as it was believed that they were profane or unholy [13].

Some superstitions are derived from an early set of views and thoughts which remain to have their impact over people's activities even though they have lost their basis of evidence through the development of rational thought based on science. In earlier days when many occurrences and events were not readily explainable, theories were invented to create seemingly sensible interpretations, such as those of involving ghosts and witches. These were intended to accommodate the desired reasons for the events which the human mind tries to explain without scientific basis. Most of these principles and theories became extinct with the advancement of science and technology, yet there are individuals and societies that are still governed or at least prejudiced by these surviving ancient concepts [15].

Scientists, physicians, and researchers have long sought to identify any basis for existing superstitious beliefs and to provide alternative explanations and practices based on rational observation and objective evidence. Solar eclipses provide an excellent 
example of this. These astronomical events have, for centuries, been the source of anxiety and numerous myths and legends. A solar eclipse is still considered to be a bad omen in several cultures. However, astronomers and behavioral scientists have extensively studied the responses of flora and fauna to solar eclipses and have determined that eclipses cause no major physical changes to humans, their heath, or the environment [7]. Some people are disinclined to wear items of clothing that have been worn by those who have felt pain or otherwise experienced bad luck, such as those who have lost a limb or contracted HIV, or by those with a strong moral taint, such as a convicted murderer or other type of felon $[16,17]$. Some also believe that microbial diseases that have caused suffering for their ancestors can also infect them. Contagion thus was explained through shared characteristics or familiarity before the discovery of the microbial basis of disease; even certain date of the year is presumed to bring ill luck $[18,19]$. Superstitious views have archaeologically been recognized as the persistent guidance of childhood considerations about the world [16]. These ascend from the rapid, automatic judgments that ordinary people have regularly used to make sense of a highly uncertain world [20-23]. 
Figure 2: Superstition can be broadly based on three different irrational behaviors and beliefs to justify certain unexplained events.

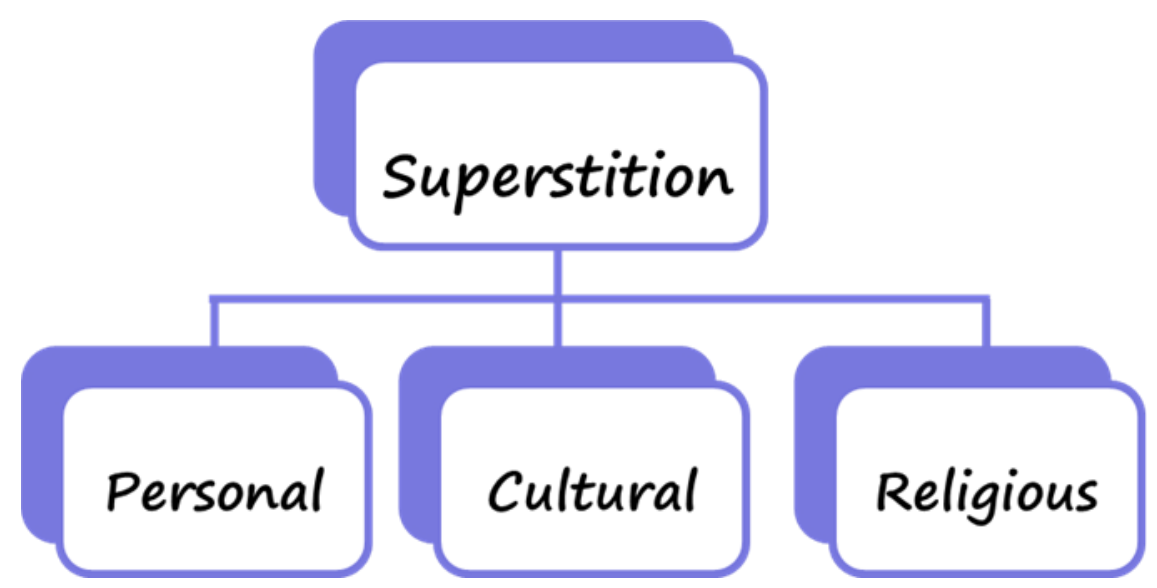

\section{Superstition and health care}

As mentioned, superstitions can be broadly grouped as religious, cultural, and personal (Figure 2). Though superstition has been declining with the advancement of science, superstitious beliefs still influence medical care. For example, patients of Kyoto University Hospital in Japan were shown to want to stay in the hospital beyond what was recommended by doctors. Researchers attributed this behavior to the patient's superstitious beliefs in being released on a lucky day versus an unlucky day. Allowing these superstitious beliefs to influence the decision when to discharge patients from the hospital significantly increased medical care costs Japan [24]. Similarly, a large percentage of the population in less educated Pakistani communities believes in the superstition that not only controls their health-seeking behavior but also factor in how the community responds to any health intervention programs. These superstitious beliefs are imperative to develop effective health programs and ensure health care delivery [25]. 
Virtually every human being, regardless of their gender, religious belief, ethnicity, educated, or ill-informed, has a fear of illness. This fear has led to the development of supernatural practices for treatment and prevention of disease where an authentic evidence-based medical care was overlooked. In the US state of Louisiana, for example, superstitious beliefs and practices were common in a subset of the population, especially in the southern part of the state, where the voodoo religion was part of their way of handling illness and fear [26]. Webb (1971) recommended that health educational programs and increased public health activities to encourage people to adopt modern health care practices and provide protection from these superstitions and voodoo practices. It was also suggested that health care professionals needed to develop skills to recognize local cultures and beliefs in order to deal with such practices that were unsafe to the health of patients [26].

Perhaps more so than superstition, religious practices still exert a profound influence on medical practices and decision-making. For instance, the family members of patients in intensive care units of three tertiary care hospitals in Greece often practiced a series of spiritual rituals, namely the use of blessed oil and holy water, the use of relics of saints and holy icons, the offering of names for pleas, and pilgrimage [27]. In Pakistan, medical students still believe, even today, that mental illnesses have paranormal, magical or mystic root causes, and also believe that mental illness can only be treated by religious, ecclesiastical, or faith-based persons [28]. Interestingly, one study found that even in the United States, work-related superstitions among health care professionals were prominent, have existed for a long time, and will probably persist into the future [29]. 
In a 2004 study to investigate work-related superstitions, 300 questionnaires were mailed out to perioperative nurses in the Pittsburgh area. While only $23 \%$ of the responders thought of themselves as superstitious, there was persistent widespread belief in certain workplace superstitions. Seventy-eight percent of the responders believed that redheaded patients were more likely to have complications such as bleeding [29]. Sixty nine percent believed that the full moon was associated with a heavier work load, and sixtysix percent believed that certain nurses work under a "black cloud" [29].

Superstitions have long been used to explain illnesses and medical phenomena when scientific rationales were not available. Many of these beliefs persist today, particularly among communities and demographics that are not regularly exposed to scientific discoveries or education. While most people in communities in both India and Pakistani have some type of superstitious beliefs, these are much more common and substantial among those who are illiterate. Often, superstitions are perpetuated in part by scammers who wish to take financial advantage of people in medical need, and who are susceptible to belief in occult powers. These beliefs can negatively impact healthcare, primarily because people will often visit a traditional or spiritual healer rather than a certified medical professional for treatment $[25,30]$. Likewise, Ghana's executive director of health has expressed his concern that Ghana's healthcare system was being held back by the fact that many Ghanaians still believed more in superstition rather than the existence of "germs" and other scientific causes for ailments [31, 32].

Understandings of these superstitious beliefs have been considered vital for the delivery of better health care and medical management in these countries. By addressing 
superstitious concerns of the people, governments and healthcare providers can conduct better outreach to offer needed medical care. Interventions which involve community participation have proven to be effective in overcoming some superstitious beliefs, but only when cultural and spiritual beliefs are approached with awareness and sensitivity [30].

\section{Conflict between superstition and medical or dental practices}

There is a natural conflict between traditional healers whose practices are based on superstition and medical professionals who strictly adhere to evidence-based medical practices. Traditional healers often use unsterilized instruments and in unsafe environments that can lead to negative, potentially fatal impacts on their patients. These practices are rejected by conventional medicine as not being scientifically suitable [3336]. Female genital mutilation, uvulectomy, oral mutilation, and eyebrow incisions are examples of superstitious practices that occur in different countries worldwide. These unscientific practices have had immediate and long-term health consequences depending on the severity and type of procedure performed [37-40]. The most common immediate consequences displayed in patients include pain, shock, septicemia, tetanus, hemorrhage, ulceration of the involved and adjacent parts, and even death. Long-term complications include abscesses, keloid scars, cysts, sexual dysfunction, and malformed and/or missing body parts [41-43].

In rare occasitions an infant might born with erupted teeth, and in ancient Rome, such infants were thought to be destined for greatness, and were dearly reffered as 
"Dentatus". On the other hand, certain tribes in Africa to the Middle East to India considered such infants with erupted teeth as evil or impure, and in worst case senerio, some of those infants were killed in the name of protecting the community. Superstition has been identified in many regions across the world, and people involved in these kinds of practices experience many negative effects on their oral and general health [44-46]. A study conducted in Ethiopia on the effects of female genital mutilation showed that respondents to a questionnaire experienced complications at the following rates: excessive bleeding during the procedure (55\%), urine retention (36\%), infection (11\%), and swelling of the genitalia (11\%) [47]. Another Tanzanian study reported that the prevalence of uvulectomy was around $4 \%$ in that region, and the most common indication for uvulectomy was cough $(81 \%)$, with the commonest reported complications were severe hemorrhage (66\%), rejecting foods (9\%), and failure to gain weight (9\%) [48]. Multiple other studies reporting on the effect of early marriage have shown that girls in the ten-to-fourteen year age range are five to seven times more likely to die from childbirth than adult women, while girls between fifteen and nineteen years of age are twice as likely to die compared to women who get married above the age of twenty years old; moreover birth injuries, serious childhood illness, with mental and physical disabilities are also associated with early marriage childbirth [49-52].

Gukura Ibyinyo or Ebinyo is a form of infant oral mutilation performed in Rwanda and parts of neighboring East African countries. It is an illegal and unsafe traditional dental procedure that traditional healers and parents have practiced on their young children in most of the East African countries. Traditional instruments are used to extract 
deciduous canines tooth buds at around six months of age. Teething babies can experience oral pain, fevers, vomiting, or diarrhea, but in traditional medicine, this is sometimes attributed to a disease called "Ibyinyo." Premature extraction of these teeth by traditional healers is believed to cure this condition. However, this practice can cause serious permanent damage to the child resulting in missing teeth and destruction of some of the surrounding permanent teeth [53-57]. A 1989 study conducted in Southern Sudan on the prevalence of Ibyinyo among the hospitalized infants found that one deciduous tooth had been removed from all the studied infants $(n=90)$, and most were suffering from dehydration caused by various other abdominal complications [58]. In another study of rural Kenyan Maasai community, a study conducted on a group of 95 children aged between six months and two years, reported that $87 \%$ of the children had removed one or more deciduous canine tooth buds. In an older age group (three to seven years of age), $72 \%$ of the 111 children examined displayed missing mandibular or maxillary deciduous canines [59]. The results of this study are similar to another one conducted in Uganda where the mean number of affected teeth per child was 3.8; of relevance, $99 \%$ of the extracted teeth were canines [60]. Between 1992 and 1998 in Uganda, the complications of Ibyinyo, including sepsis and anemia, were leading causes of hospital admission and hospital death (with a case fatality rate of $21 \%$ and a proportional mortality rate of $3 \%)$ [42]. 


\section{Conclusion}

Certain traditional practices are a public health concern that contradicts conventional medical professional practices. These can affect the oral and general health of the affected population, depending on the type of practice performed. Such types of practices are being spread to other parts of the world by immigration or settlement. It is not easy to change the mindset of the people who keep practicing these old habits, however, education programs that take into the consideration of the sensitivity of the cultural and religious aspects of traditional practices are the best hope of eradicating these harmful practices (Figure 3).

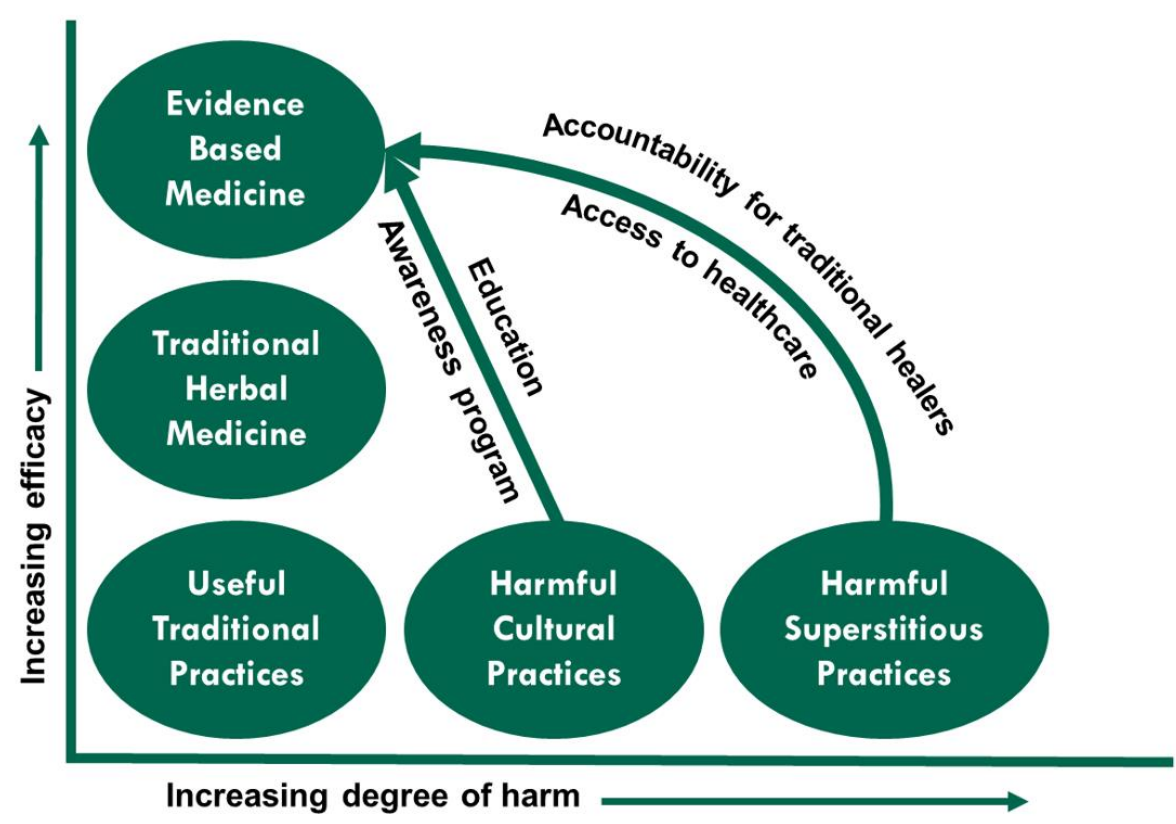

Figure 3: Simplified diagram showing the role of education, awareness, and availability of health care in the battle against harmful cultural and superstitious practices. Acupuncture is an excellent example of useful traditional practice, while, oral mutilation ("Ibyinyo") is an example of harmful cultural practice. Physical and/or emotional torture of mentally disabled individuals is an example of the harmful superstitious practice. 
The following recommendations would likely to reduce unprofessional superstition-based harmful practices in society:

- Awareness of professional health education and promotion in the communities to prevent the practices of these unprofessional traditional practices.

- Medical and other Health professionals should educate the community on the harmful effects of traditional practices through community health outreaches.

- The danger of blood borne infections like HIV that may occur due to these practices should be emphasized.

- Availability, accessibility and quality of professional healthcare services in the community should be improved.

- Harmful consequences of unsafe traditional health practices should be included in all health science curricula.

- Traditional healers should be held accountable for unprofessional acts. 


\section{References}

1. Cleland, C.E., Historical science, experimental science, and the scientific method. Geology, 2001. 29(11): p. 987-990.

2. Fischer, M.R. and G. Fabry, Thinking and acting scientifically: Indispensable basis of medical education. GMS Zeitschrift für Medizinische Ausbildung, 2014. 31(2).

3. Ziman, J.M., The proliferation of scientific literature: a natural process. Science, 1980. 208(4442): p. 369-371.

4. Abraham, R.R., et al., Clinically oriented physiology teaching: strategy for developing critical-thinking skills in undergraduate medical students. Advances in physiology education, 2004. 28(3): p. 102-104.

5. Ezzo, J., et al., Reviewing the reviews: how strong is the evidence? How clear are the conclusions? International Journal of Technology Assessment in Health Care, 2001. 17(4): p. 457-466.

6. Brooks, S. and N. Biala, A searchable database of medical education objectivescreating a comparable gold standard. BMC medical education, 2018. 18(1): p. 31.

7. Zirker, J.B., Total eclipses of the sun. Science, 1980. 210(4476): p. 1313-9.

8. Vyse, S.A., Believing in magic: The psychology of superstition-updated edition. 2013, Oxford: Oxford University Press.

9. Berger, A.S., The evil eye-An ancient superstition. Journal of religion and health, 2012. 51(4): p. 1098-1103.

10. Risen, J.L., Believing what we do not believe: Acquiescence to superstitious beliefs and other powerful intuitions. Psychological Review, 2016. 123(2): p. 182.

11. Tanaka, C.M. and Y. Iwasa, Cultural evolution of a belief controlling human mate choice: Dynamic modeling of the hinoeuma superstition in Japan. Journal of theoretical biology, 2012. 309: p. 20-28.

12. Dömötör, Z., R. Ruíz-Barquín, and A. Szabo, Superstitious behavior in sport: A literature review. Scandinavian journal of psychology, 2016. 57(4): p. 368-382.

13. Crawfurd, R., Of Superstitions concerning Menstruation. Proc R Soc Med, 1916. 9(Sect Hist Med): p. 49-66.

14. Umeora, O. and V. Egwuatu, Menstruation in rural Igbo women of south east Nigeria: attitudes, beliefs and practices. African journal of reproductive health, 2008. 12(1): p. 109-115.

15. SUPERSTITIONS IN MEDICINE. JAMA, 2006. 295(1): p. 113-113.

16. Rozin, P. and C. Nemeroff, The laws of sympathetic magic, in Cultural Psychology: Essays on Comparative Human Development, G. Herdt, J.W. Stigler, and R.A. Schweder, Editors. 1990, Cambridge University Press: Cambridge. p. 205-232.

17. Rozin, P. and C. Nemeroff, Sympathetic Magical Thinking: The Contagion and Simi- larity Heuristics. The psychology of intuitive thought. 2002, New York: Cambridge University Press. 
18. Exadaktylos, A.K., et al., Friday the 13th and full-moon the" Worst Case Scenario" or only superstition? The American journal of emergency medicine, 2001. 19(4): p. 319-320.

19. Golooba-Mutebi, F. and S.M. Tollman, Confronting HIV/AIDS in a South African village: The impact of health-seeking behaviour 1. Scandinavian Journal of Public Health, 2007. 35(69_suppl): p. 175-180.

20. Foster, K.R. and H. Kokko, The evolution of superstitious and superstition-like behaviour. Proceedings of the Royal Society B: Biological Sciences, 2008. 276(1654): p. 31-37.

21. Tversky, A. and D. Kahneman, Availability: A heuristic for judging frequency and probability. Cognitive Psychology, 1973. 5(2): p. 207-232.

22. Tversky, A. and D. Kahneman, Judgment under Uncertainty: Heuristics and Biases. Science, 1974. 185(4157): p. 1124.

23. Tversky, A. and D. Kahneman, Extensional versus intuitive reasoning: The conjunction fallacy in probability judgment. Psychological Review, 1983. 90(4): p. 293-315.

24. Hira, K., et al., Influence of superstition on the date of hospital discharge and medical cost in Japan: retrospective and descriptive study. BMJ, 1998. 317(7174): p. 1680-3.

25. Bukhari, S.S., et al., Superstitions regarding health problems in different ethnic groups in Karachi. J Pak Med Assoc, 2002. 52(8): p. 383-7.

26. Webb, J.Y., Louisiana voodoo and superstitions related to health. HSMHA Health Rep, 1971. 86(4): p. 291-301.

27. Fouka, G., et al., Health-related religious rituals of the Greek Orthodox Church: their uptake and meanings. J Nurs Manag, 2012. 20(8): p. 1058-68.

28. Waqas, A., et al., Public stigma associated with mental illnesses in Pakistani university students: a cross sectional survey. Peer], 2014. 2: p. e698.

29. Mandell, D.L., M.L. Claypool, and D.J. Kay, Superstitions among perioperative nurses. AORN J, 2005. 81(5): p. 971-984.

30. Sharma, S., et al., Superstitions in Urban Community Affecting Health: Assessment and Interventional study in Meerut, India. SMU Medical Journal, 2016. 3(1): p. 606-615.

31. Superstition is a drawback to Ghana's health care system -Prof Akosa. 2014 [cited 2017 February 10, 2017]; Available from:

http://www.myjoyonline.com/news/2014/march-30th/superstition-is-a-drawbackto-ghanas-health-care-system-prof-akosa.php.

32. Tenkorang, E.Y., et al., Superstition, witchcraft and HIV prevention in subSaharan Africa: The case of Ghana. Culture, health \& sexuality, 2011. 13(9): p. 1001-1014.

33. Hillard, J.R. and W.J. Rockwell, Dysesthesia, witchcraft, and conversion reaction. A case successfully treated with psychotherapy. JAMA, 1978. 240(16): p. 17424.

34. Ijaduola, G.T., Uvulectomy in Nigeria. J Laryngol Otol, 1981. 95(11): p. 1127-33. 
35. Miles, S.H. and H. Ololo, Traditional surgeons in sub-Saharan Africa: images from south Sudan. Int J STD AIDS, 2003. 14(8): p. 505-8.

36. Wein, S., Cancer, unproven therapies, and magic. Oncology (Williston Park), 2000. 14(9): p. 1345-50; discussion 1355-9.

37. Bjalkander, O., et al., Health complications of female genital mutilation in Sierra Leone. Int J Womens Health, 2012. 4: p. 321-31.

38. Komolafe, O.O., et al., African traditional medication and keloid formation in herpes zoster ophthalmicus. Niger J Clin Pract, 2011. 14(4): p. 479-81.

39. Manni, J.J., Uvulectomy, a traditional surgical procedure in Tanzania. Ann Trop Med Parasitol, 1984. 78(1): p. 49-53.

40. Pallangyo, P., et al., Human immunodeficiency virus infection acquired through a traditional healer's ritual: a case report. J Med Case Rep, 2017. 11(1): p. 301.

41. Ezenyeaku, C., et al., Survey of Women's Opinions on Female Genital Mutilation (FGM) in Southeast Nigeria: Study of Patients Attending Antenatal Clinic. Ann Med Health Sci Res, 2011. 1(1): p. 15-20.

42. Iriso, R., et al., 'Killer' canines: the morbidity and mortality of ebino in northern Uganda. Trop Med Int Health, 2000. 5(10): p. 706-10.

43. Shah, G., L. Susan, and J. Furcroy, Female circumcision: history, medical and psychological complications, and initiatives to eradicate this practice. Can J Urol, 2009. 16(2): p. 4576-9.

44. Albertyn, R., et al., Traditional burn care in sub-Saharan Africa: a long history with wide acceptance. Burns, 2015. 41(2): p. 203-11.

45. Reid, S.R., Injections that kill: nosocomial bacteraemia and degedege in Tanzania. Rural Remote Health, 2010. 10(3): p. 1463.

46. Withers, M., N. Kharazmi, and E. Lim, Traditional beliefs and practices in pregnancy, childbirth and postpartum: A review of the evidence from Asian countries. Midwifery, 2018. 56: p. 158-170.

47. Bogale, D., D. Markos, and M. Kaso, Prevalence of female genital mutilation and its effect on women's health in Bale zone, Ethiopia: a cross-sectional study. BMC Public Health, 2014. 14: p. 1076.

48. Machumu, R.S. and F.M. Fabian-Taylor, The practice of uvulectomy and related complications among children aged below 6 years in Ilemela district, Mwanza, Tanzania. Tanzania Dental Journal, 2008. 15(1): p. 10-14.

49. Monroy De Velasco, A., Consequences of early childbearing. Draper Fund Rep, 1982(11): p. 26-7.

50. Saxena, P., et al., Obstetric and perinatal outcome of teenage and older primigravidas-a retrospective analysis. Health and Population: Perspectives and Issues, 2010. 33(1): p. 16-22.

51. Stokoe, U., Determinants of maternal mortality in the developing world. Aust N Z J Obstet Gynaecol, 1991. 31(1): p. 8-16.

52. Suwal, A., Obstetric and perinatal outcome of teenage pregnancy. J Nepal Health Res Counc, 2012. 10(1): p. 52-6. 
53. Bataringaya, A., M. Ferguson, and R. Lalloo, The impact of ebinyo, a form of dental mutilation, on the malocclusion status in Uganda. Community Dent Health, 2005. 22(3): p. 146-50.

54. Edwards, P.C., et al., Extirpation of the primary canine tooth follicles: a form of infant oral mutilation. J Am Dent Assoc, 2008. 139(4): p. 442-50.

55. Kemoli, A., et al., Prevalence and impact of infant oral mutilation on dental occlusion and oral health-related quality of life among Kenyan adolescents from Maasai Mara. BMC Oral Health, 2018. 18(1): p. 173.

56. Pope, E.A., et al., Infant Oral Mutilation. Case Rep Dent, 2018. 2018: p. 7586468.

57. Wandera, M.N. and B. Kasumba, "Ebinyo"-The Practice of Infant Oral Mutilation in Uganda. Front Public Health, 2017. 5: p. 167.

58. Baba, S.P. and E.J. Kay, The mythology of the killer deciduous canine tooth in southern Sudan. J Pedod, 1989. 14(1): p. 48-9.

59. Hassanali, J., P. Amwayi, and A. Muriithi, Removal of deciduous canine tooth buds in Kenyan rural Maasai. East Afr Med J, 1995. 72(4): p. 207-9.

60. Tirwomwe, J., E. Agwu, and M. Ssamula, The magnitude of tooth bud extraction in Uganda. International Journal of Medicine and Medical Sciences, 2013. 5(10): p. $450-455$. 